\title{
Protective Effect of Soy Isoflavones (from Glycine max) on Adipose Tissue Oxidative Stress and Inflammatory Response in an Experimental Model of Post-menopausal Obesity: The Molecular Mechanisms
}

\section{Sankar Panneerselvam ${ }^{1,2}$, Rajaa Muthu Packirisamy ${ }^{1}$, Zachariah Bobby ${ }^{1 *}$ and Magadi Gopalakrishna Sridhar ${ }^{1}$}

${ }^{1}$ Department of Biochemistry, Jawaharlal Institute of Postgraduate Medical Education and Research, Puducherry, India

${ }^{2}$ Molecular and Nanomedicine Research Unit, Centre for Nanoscience and Nanotechnology, Sathyabama University, Jeppiaar Nagar, Chennai, India

\begin{abstract}
Obesity, adiposity mediated oxidative stress and inflammatory response has been identified to have an etiological origin for most of the complications associated with ageing populace. However, there are limited studies addressing the metabolic role of adipose tissue in the pathobiology of postmenopausal complications with respect to oxidative stress and inflammation. Numerous studies have reported the beneficial effects of soy isoflavones on postmenopausal complications; however, its efficacy these complications in postmenopausal model of obesity remain unclear. In the present study we found that the both ovariectomy and high fat diet (30 per cent fat) in isolation and in combination developed adipose tissue oxidative stress as evidenced by the reduced level of total antioxidant status (TAS) in association with elevated levels of adipose tissue malondialdehyde (MDA) and MDA/TAS ratio. These rats also displayed with inflammation as showed by increased levels of plasma tumor necrosis factor alpha (TNFa) and high sensitive $\mathrm{C}$ - reactive protein (hsCRP). The expression of adipose tissue inflammatory proteins; cyclo-oxygenase 2 (COX2), monocyte chemo attractant protein (MCP1) and protein kinase $\mathrm{C}$ alpha (PKCa) were heightened in response to both ovariectomy and high fat diet. All these metabolic changes were further augmented when ovariectomy was followed by high fat diet. This suggests that there was a synergism between the postmenopausal state and intake of fat rich diet in the development of adipose tissue oxidative stress and inflammatory response. Treatment with soy isoflavones significantly inhibited these metabolic changes improved adipose tissue oxidative stress and inflammatory response suggesting the use of this natural phytoestrogen as an anti-oxidant and anti-inflammatory agent for relieving metabolic consequences associated with postmenopausal women.
\end{abstract}

Keywords: Menopause; Obesity; Oxidative stress; Inflammation; Soy isoflavones

\section{Introduction}

During past few years, studies have focused the relation between the oxidative stress and inflammation in response to ageing and most of the metabolic diseases have been identified to have an etiological origin of inflammation that the term "inflammaging" has been coined [13]. Hence, developing the strategies to prevent or to reduce the development of inflammation in the aging population has become a priority ingeron to logical research in recent years. Menopause, an agerelated loss of ovarian function adds further complexity to the aging milieu. While the average age for menopause in India is 47.5 years, recent reports also indicate an alarming rise in premature menopause among Indian women [4]. The ground for this early menopause is still unclear, but it is a severe public health problem because of its influence on the development of metabolic syndrome. During menopause, many women experience weight gain and accumulation of body fat in the waist region [5].

Increased visceral adiposity and obesity associated with the agerelated loss of ovarian function are implicated in the pathology of cardiovascular diseases (CVD) [6]. In addition to the genetic predisposition for obesity, the environmental factors like diet induced obesity unique to the present generation can worsen this scenario. Imbalance of Redox status and pro- versus anti-inflammatory cytokines has been identified as a potential mechanism involved in the etiology of CVD associated with menopause [7-10]. Increased tumor necrosis factor alpha (TNF $\alpha)$ expression in association with oxidative stress has been reported in response to estrogen deficiency which coincides with increased CVD risk associated with menopause [11]. In addition, the postmenopausal period is markedly associated with elevated levels of cytokines such as interleukin 6 (IL-6), TNFa and IL-1 [12,13]. Controversially, studies also reported that the inflammatory cytokines levels were elevated in the early stage of the menopause (less than five years) and return to the normal levels in the late stage, with values similar to pre menopause phase [14]. Thus, it is not clear whether estrogen deficiency could lead to an inflammatory state in postmenopausal women. Therefore, the etiology of inflammation in postmenopausal women is still a complex issue and further studies should be carried out to explore the same.

Estrogen replacement therapy (ERT) has been shown to be protective against many meno pause- related metabolic abnormalities. However, long term usage of ERT might increases the risk of certain cancer; endometrial and breast cancer in addition to its negative implications for CVD in postmenopausal women [15-17]. At present, there are no specific/ effective pharmacological strategies available in the management of metabolic consequences concomitant with postmenopausal population [18]. Thus, there is an acute need of novel drugs of natural or synthetic origin possessing minimal adverse effects to replace the currently used ERT.

Isoflavones, mainly derived from soybean are a group of biologically active substances shares the structural and functional

*Corresponding author: Zachariah Bobby, Professor and Head of Biochemistry, JIPMER, Puducherry-605 006, India, Tel: + 91 8056448984; E-mail: sankarjipmer@gmail.com

Received: February 23, 2016; Accepted: April 18, 2016; Published April 21, 2016

Citation: Panneerselvam S, Packirisamy RM, Bobby Z, Sridhar MG (2016) Protective Effect of Soy Isoflavones (from Glycine max) on Adipose Tissue Oxidative Stress and Inflammatory Response in an Experimental Model of Post-menopausal Obesity: The Molecular Mechanisms. Biochem Anal Biochem 5: 266. doi:10.4172/2161. 1009.1000266

Copyright: (c) 2016 Panneerselvam S, et al. This is an open-access article distributed under the terms of the Creative Commons Attribution License, which permits unrestricted use, distribution, and reproduction in any medium, provided the original author and source are credited. 
Citation: Panneerselvam S, Packirisamy RM, Bobby Z, Sridhar MG (2016) Protective Effect of Soy Isoflavones (from Glycine max) on Adipose Tissue Oxidative Stress and Inflammatory Response in an Experimental Model of Post-menopausal Obesity: The Molecular Mechanisms. Biochem Anal Biochem 5: 266. doi:10.4172/2161-1009.1000266

Page 2 of 7

homogeneity with estrogen [19]. Epidemiological studies have demonstrated a reduced mortality rate due to coronary heart disease in populations consuming soy food [20] and other studies also suggests that is of lavones derived from soy beans may have antiinflammatory activity in CVD [21]. A number of studies have reported beneficial effects of soy isoflavones against inflammatory response [2226]. However, some of the studies have not observed beneficial effects [27-30]. Though most of the soy isoflavones studies have focused on postmenopausal population, the ability of soy isoflavones to modulate the underlying inflammatory response involved in this population has not been assessed. Therefore, the purpose of this study was twofold; first, to elucidate the molecular mechanisms underlying the pathogenesis of inflammation in postmenopausal obesity and second, to investigate the anti-inflammatory activity of soy isoflavones at molecular level in an experimental model of postmenopausal obesity.

\section{Materials and Methods}

\section{Chemicals}

All the chemicals were of molecular reagent-grade and were purchased from Sigma Chemicals (St. Louis, MO, USA). The nitrocellulose membrane and CL-Xposure films were from Amersham (Amersham Hybond-ECL membrane, GE Healthcare, Little Chalfont, Buckinghamshire, UK). The enhanced chemiluminescence substrate (ECL) was from Pierce, WestPico Super Signal (Thermo Fisher Scientific, Marietta, USA). The primary antibodies against the rat cyclo-oxygenase 2 (COX2) was purchased from cell signaling technology (CST, Berverly, MA), antibody for Monocyte chemoattractant protein1(MCP1)from Thermoscientific Fishers (Thermo Fisher Scientific, Marietta, USA) and antibodies for total and phosphorylated protein kinase $\mathrm{C}$ alpha (PKCa) were from Millipore Antibodies (Millipore Antibodies, CA, USA). The anti-rabbit and anti-mouse IgG HRP linked secondary antibodies were from Santa Cruz (Santa Cruz Biotechnology, Santa Cruz, CA, USA).

\section{Experimental design}

The animal experiment was conducted in the Department of Biochemistry, JIPMER, Puducherry, India after Institutional Animal ethical committee approval. Three month old female Wistar rats were obtained from the host institute and housed in plastic polycarbonate cages with a 12 hour dark/light cycles with food and water available ad libitum. Sixty four rats were used for the study and were randomized into eight different groups (8 rats in each group). Blood samples were collected at 3 stages:1) Basal-Atthebeginningofthestudy,2) Phase1-Fourweeksafter ovariectomy, 3) Phase 2-Eight weeks after the completion of Phase 1 . The schematic representation of randomization of rats and experimental treatments was described in Figure 1.

\section{Preparation of high fat diet}

The semi purified high-fat diet was prepared as described by Strolein et al. with $59 \%$ of total calories derived from fat, $21 \%$ from protein, and $20 \%$ from carbohydrate. The energy of the high-fat diet was $5.2 \mathrm{kcal} / \mathrm{g}$ whereas that of the chow diet was $3.3 \mathrm{kcal} / \mathrm{g}$ [31].

\section{Surgical procedure for bilateral ovariectomy}

The animal was anesthetized under ketamine anesthesia $(100 \mathrm{mg} / \mathrm{Kg}$ body weight). The ventral aspect of animal was shaven and cleaned with $70 \%$ alcohol and then with sterile saline. A single midline $2-3 \mathrm{~cm}$ long incision was made under sterile conditions. The ovaries were located and excised. The incision was then sutured using aseptic techniques and wiped clean with sterile saline. Antibiotic cream was applied locally over the wound. The success of the bilateral ovariectomy was confirmed histologically (Figure 2).

\section{Methanolic extraction of soy isoflavones}

The soybean hypocotyls were purchased from local market (PAPSCO, Puducherry, India). Isoflavones were extracted from soybean hypocotyls according to the method described by Yoon-Bok Lee, et al. [32]. The soybean hypocotyls were mixed with 10 volumes of $80 \%$ aqueous methanol and stirred for $4 \mathrm{hrs}$ at room temperature. The methanolic extract was then concentrated in a rotary evaporator at 500C. The final step of the preparation involved freeze-drying the concentrated methanol extract. In those groups of rats were isoflavones were administered, it was given mixed in drinking water at a dose of $150 \mathrm{mg} / \mathrm{kg}$ body weight/day [33].

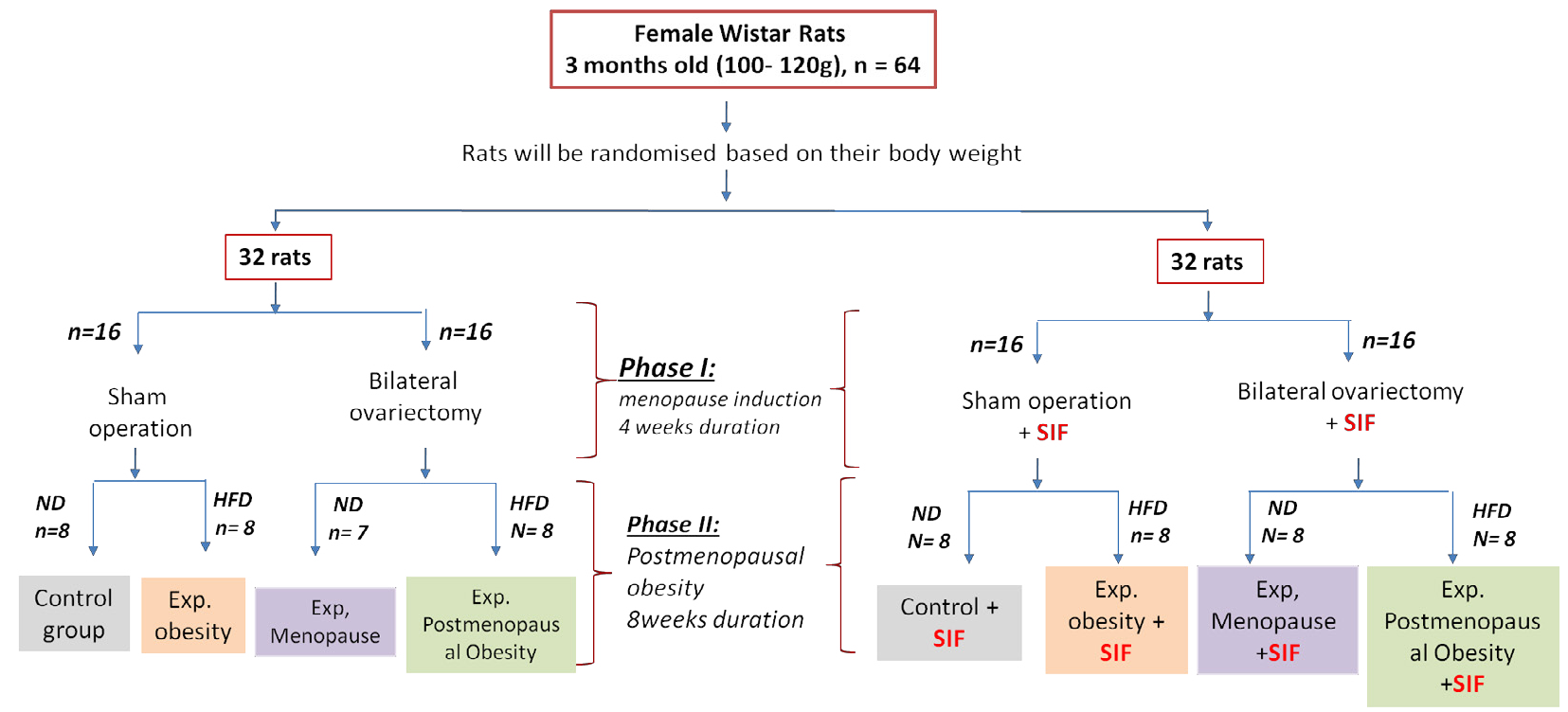

Figure 1: Schematic representation of experimental groups. Rats were undergone both sham operated or bilateral ovariectomised, and then they were fed with either normal chow or high fat diet in the presence and absence of soy isoflavones in the dose $150 \mathrm{mg} / \mathrm{kg} \mathrm{BW}$ for 12 weeks. ND - Normal Diet, HFD - High Fat Diet, Exp. Experimental, SIF - Soy Isoflavones. 
Citation: Panneerselvam S, Packirisamy RM, Bobby Z, Sridhar MG (2016) Protective Effect of Soy Isoflavones (from Glycine max) on Adipose Tissue Oxidative Stress and Inflammatory Response in an Experimental Model of Post-menopausal Obesity: The Molecular Mechanisms. Biochem Anal Biochem 5: 266. doi:10.4172/2161-1009.1000266

Page 3 of 7

\section{Blood sample collection}

Blood samples were collected at basal, after four weeks of surgery (phase I) and at the end of the HFD (phase 2) to evaluate inflammatory responses. The animals were then sacrificed; the organs such as liver, kidney and adipose tissues were snap frozen immediately in liquid N2 and subsequently used for future studies. The plasma was separated from the blood by centrifuging the whole blood at $8000 \mathrm{rpm}$ for $5 \mathrm{mins}$. The plasma was separated by centrifuging the whole blood at 6000 rpm for 10 mins. Then the separated plasma was used for biochemical analysis.

\section{Measurement of plasma oxidative stress and inflammatory response}

The fasting plasma inflammatory marker; tumor necrosis factor alpha (TNFa, GEN-PROBEDia - CloneSAS, 25020 Besancon Cedex, France), was estimated by enzyme linked immunosorbent assay (ELISA) according to the manufacturer's instructions. The oxidative stress parameter such as plasma malondialdehyde (MDA) was estimated by the method of Yagi, et al. [34].

\section{Estimation of adipose tissue oxidative stress parameters}

For the assessment of oxidant/antioxidant status of the adipose tissue, the tissues were homogenized with phosphate buffered saline (PBS, pH 7.6). The homogenate malondialdehyde (MDA) and total antioxidant status (TAS) were estimated and the values were expressed as $\mu \mathrm{mol} / \mathrm{mg}$ of proteins [34]. The total antioxidant status (TAS) was measured by the method of Benzie and Strain [35]. The index of oxidative stress was calculated mathematically using the formula MDA/ TAS $[36,37]$

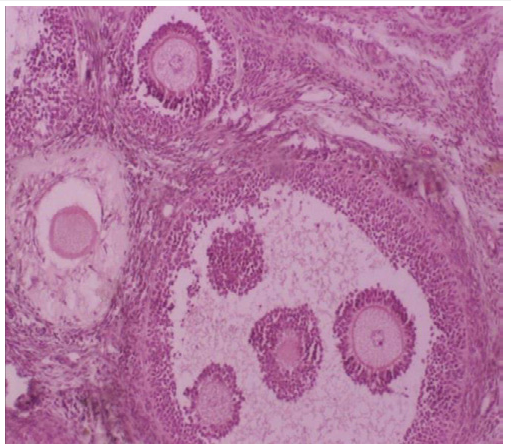

Figure 2: Histological confirmation of successful of bilateral ovariectomy. Image was captured using Olympus BX43 Cell Culture inverted microscopy (Olympus, Japan) at $10 \mathrm{X}$ magnification.

\section{Analysis of adipose tissue inflammatory signaling}

Adipose tissues $(100 \mathrm{mg} / 250 \mathrm{ul})$ were homogenized with appropriate homogenizing buffer (RIPA buffer $\mathrm{pH}-8.6$ containing; $150 \mathrm{mM} \mathrm{NaCI}$, $1 \%$ NP-40, $0.5 \%$ sodium deoxy cholate, $0.1 \%$ SDS, $50 \mathrm{mM}$ Tris, $5 \mathrm{mM}$ EDTA, $1 \mathrm{mM}$ EGTA, $10 \mathrm{mM}$ sodium fluoride, $20 \mathrm{mM}$ DTT, $1 \mathrm{mM}$ Benzamidine HCI, 1mM PMSF, 1uM Aprotinin, Pepstatin A and Okadaic acid) and sonication was done 3 times (5 seconds each) at one minute interval at 20 pulses. The homogenate was then centrifuged at $12,000 \mathrm{rpm}$ for 20 minutes at $40 \mathrm{C}$ and supernatant was separated and protein concentrations were measured by Lowry's method [37]. Equal amounts of protein were separated by sodium dodecylsulfate polyacrylamidegel electrophoresis (Bio-Rad, China) and transferred immediately on to the nitrocellulose membranes using Trans SD semidry transfer (Bio-Rad, China). Membranes were blocked with 5\% $\mathrm{w} / \mathrm{v}$ bovine serum albumin (BSA) or non - fat milk powder for one hour at room temperature and subsequently were incubated in $5 \%$ w/v BSA or non-fat milk powder in Tris Buffed Saline-0.1\%Tween 20 (TBS-T) with specific primary antibodies overnight at $4^{\circ} \mathrm{C}$ as per the recommended dilution. Membranes were then washed 3 times with TBST and subsequently incubated with species-appropriate, peroxidase-conjugated secondary antibodies for 1 hour at room temperature. Blots were washed 3 times with TBST and visualization was performed with ECL kit reagent according to the manufacturer's instruction, followed by autoradiography using the same. Bands were scanned and their average densities were determined by using Image Densitometer GS-710 (Bio-Rad, China). To reprobe with other antibodies, the membranes were stripped in stripping buffer $(62.5 \mathrm{mM}$ tris-HCI, $2 \%$ SDS, $100 \mathrm{mM}$ beta mercaptoethanol, $\mathrm{pH}$ 6.8) for $30 \mathrm{mins}$ at $500 \mathrm{C}$ with mild agitation.

\section{Statistical analysis}

Data are expressed as mean \pm SD. Differences among groups were analyzed using one way measures of analysis of variance (ANOVA) with Tukey post hoc test. Statistical Package of Social Service (SPSS, Version 19.0) was used for analysis. An associated probability (P value) less than $0.05 \%$ was considered as statistically significant.

\section{Results}

\section{Effect of soy isoflavones extract on body weight adipose weight}

Both ovariectomy and high fat diet feeding in rats showed increased body weight and adipose tissue mass. The increment in the body weight as well as adipose mass was further increased when ovariectomy was followed by high fat diet (Table 1). Treatment with soy isoflavones

\begin{tabular}{|c|c|c|c|c|}
\hline Parameters & Whole body weight (grams) & $\begin{array}{l}\text { Relative liver weight } \\
\quad(\mathrm{g} / 100 \mathrm{~g} \mathrm{BW})\end{array}$ & $\begin{array}{c}\text { Relative adipose weight (g/100g } \\
\text { BW) }\end{array}$ & $\begin{array}{c}\text { Relative uterus weight }(\mathrm{g} / 100 \mathrm{~g} \\
\text { BW) }\end{array}$ \\
\hline$C(n=8)$ & $150.8 \pm 7.36$ & $2.2 \pm 0.18$ & $2.6 \pm 0.15$ & $0.51 \pm 0.08$ \\
\hline$O(n=7)$ & $168.8 \pm 6.13$ * & $3.1 \pm 0.22^{*}$ & $3.1 \pm 0.27^{*}$ & $0.41 \pm 0.04$ \\
\hline $\begin{array}{c}H(n=8) \\
0+H(n=8)\end{array}$ & $\begin{array}{c}223 \pm 9.7^{*} \\
231.3 \pm 10.06^{*}, ¥, \phi\end{array}$ & $\begin{array}{c}3.5 \pm 0.53^{*} \\
4.3 \pm 0.39^{*}, ¥, \phi\end{array}$ & $\begin{array}{c}3.3 \pm 0.24^{*} \\
3.9 \pm 0.55^{*}, ¥, \phi\end{array}$ & $\begin{array}{l}0.35 \pm 0.05 \\
0.29 \pm 0.02\end{array}$ \\
\hline $\begin{array}{l}C+\operatorname{SIF}(n=8) \\
O+\operatorname{SIF}(n=8)\end{array}$ & $\begin{array}{c}\text { 143. } \pm 9.16 \\
149.3 \pm 4.37 ¥\end{array}$ & $\begin{array}{l}2.1 \pm 0.11 \\
2.6 \pm 0.31\end{array}$ & $\begin{array}{c}2.4 \pm 0.2 \\
2.6 \pm 1.11\end{array}$ & $\begin{array}{l}0.57 \pm 0.10 \\
0.49 \pm 0.03\end{array}$ \\
\hline$H+\operatorname{SIF}(n=8)$ & $202.7 \pm 8.82 ¥$ & $3.1 \pm 0.16$ & $3.1 \pm 0.23$ & $0.41 \pm 0.06$ \\
\hline$O+H+S I F(n=8)$ & $207.3 \pm 8.62 \phi$ & $4.0 \pm 0.48$ & $3.8 \pm 0.46$ & $0.35 \pm 0.03$ \\
\hline
\end{tabular}

All the values are expressed as mean $\pm \mathrm{SD}$ ( $\mathrm{n}=8$ per group). ${ }^{*} ¥, \phi \mathrm{P}<0.05$ considered as statistically significant. * - in comparison with $\mathrm{C}$, $¥-$ in comparison with $\mathrm{O}, \phi-$ in comparison with $\mathrm{H}, \$-$ in comparison with O + H, (one way ANOVA followed by Tukey post hoc test, SPSS version 19.0). C - Control, O - Ovariectomy, H - High Fat Diet, SIF - Soy Isoflavones, BW - Body Weight.

Table 1: Effect of soy isoflavones extract on body weight and other organs weight in an experimental model of postmenopausal obesity. 
Citation: Panneerselvam S, Packirisamy RM, Bobby Z, Sridhar MG (2016) Protective Effect of Soy Isoflavones (from Glycine max) on Adipose Tissue Oxidative Stress and Inflammatory Response in an Experimental Model of Post-menopausal Obesity: The Molecular Mechanisms. Biochem Anal Biochem 5: 266. doi:10.4172/2161-1009.1000266

Page 4 of 7

extract significantly reduced body weight and adipose weight in both ovariectomised rats as well as high fat fed rats.

\section{Effects of soy isoflavones on plasma oxidative stress and inflammatory markers}

The Figure 3 shows the effects of soy isoflavones on ovariectomy and high fat diet induced plasmalipid peroxidation and inflammatory marker TNFa. Ovariectomy and high fat feeding in rats caused as increased plasma levels of malondialdehyde (MDA) and TNFa and this effect was further aggravated when ovariectomy was combined with high fat diet. Treatment with soy isoflavones significantly inhibited the ovariectomy and high fat diet induced elevation in these oxidative stress and inflammatory parameters and improved oxidative stress and inflammatory response in these rats. Effects of soy isoflavones

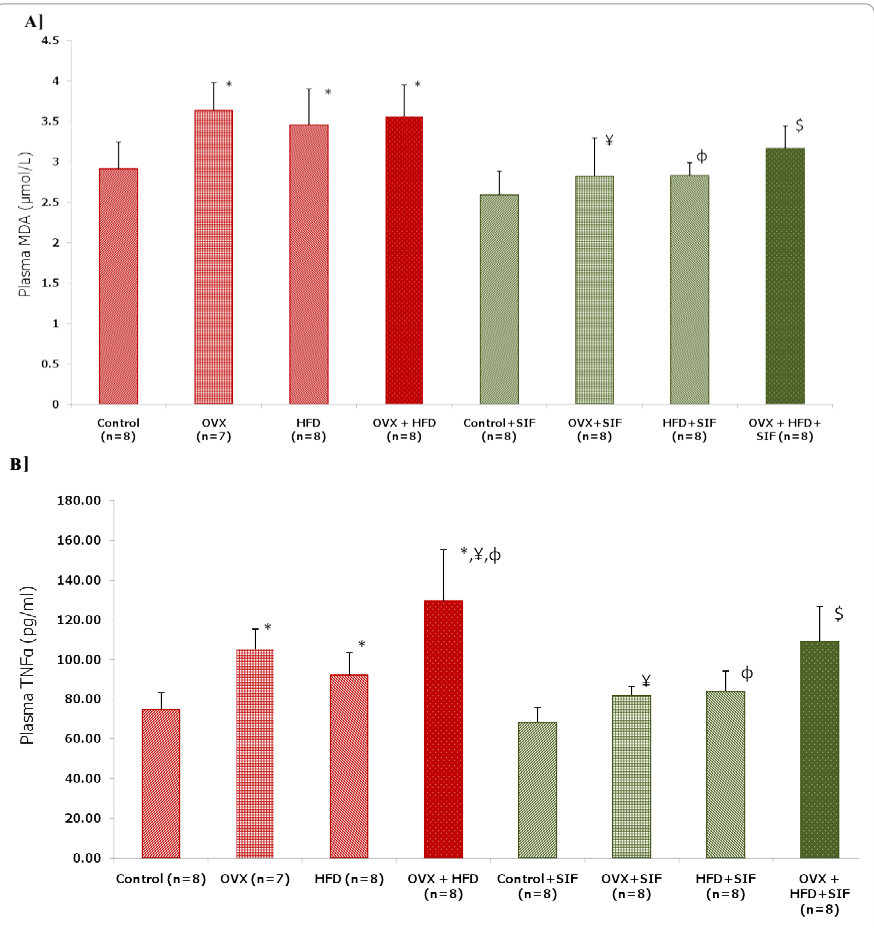

Figure 3: Effect of soy isoflavones on plasma oxidative stress and inflammation in high fat fed ovariectomised female Wistar rats. A) Plasma MDA, B) Plasma TNFa. Results expressed as mean \pm S.D. $(n=8)$. * $, \neq, \phi, \$ P<0.05$ considered as statistically significant, * in comparison with $C, ¥$ in comparison with OVX, $\phi$ in comparison with HFD, \$ in comparison with OVX+HFD). C - Control, OVX - ovariectomy, HFD - High Fat Diet, SIF - Soy Isoflavones, MDA Malondialdehyde, TNF - Tumor Necrosis Factor, (One way analysis of variance with Tukey post hoc test, SPSS $\vee$ 16.0) on adipose tissue oxidative stress: The adipose tissue oxidative stress markers; malondialdehyde (MDA) and oxidative stress index (OSI = MDA/TAS) were increased and total antioxidant status was reduced in response to both ovariectomy and high fat diet, with a more pronounced effects when both were combined. The increase in these oxidative stress markers were significantly inhibited by the use of soy isoflavones in all the experimental rats.

\section{Effects of the soy isoflavones on the expression of adipose tis- sue inflammatory proteins}

Ovariectomy and high fatdiet, by alone and by their combination caused enhanced expression of inflammatory proteins such as COX2, MCP1 and increased activation of PKCa in adipose tissues. In addition, the enhanced expression of these inflammatory proteins was further augmented when the ovariectomy was combined with high fat diet. Treatment with soy isoflavones extract significantly reduced the ovariectomy as well as high fat diet induced expression of COX2, MCP1 and the increased activation of PKCa in adipose tissue (Table 2) (Figures 4-6)

\section{Discussion}

Premeno pausal women are found to be protected from the risk of developing the inflammatory mediated obesity and its associated cardiovascular complications compared to their men peers. After menopause this protection is lost due to change in the sex hormone profile. The magnitude of the problem is substantial due to the significant number of women in this age group all over the world. Obesity, and in particular visceral adiposity after meno pause, is positively associated with chronic adipose tissue inflammation, which is now implicated as an underlying cause of obesity-associated metabolic complications $[38,39]$. However, the pathological mechanisms remain unclear. The major finding of the present study was both ovariectomy and high fat diet feeding in rats caused inflammatory response, with a more augmented effect when both where combined. This suggests that there was asynergism between the post meno pausal state and intake of fat rich diet in the development of inflammatory response. Treatment with soy isoflavones significantly restored the inflammatory response in these rats suggesting the use of this natural phytoestrogen as a strategy for relieving the inflammatory response in this population.

In the present study we observed that both ovariectomy and high fat diet, by themselves and by their combination caused inflammatory response as evidenced by elevated levels of plasma TNFa and CRP. The expression of key inflammatory cytokines like COX2, MCP1 and activation of PKCa were also heightened in the adipose tissue of ovariectomised rats and high fat fed rats. These finding are in line with the previous studies [40-43]. The increase in these pro-inflammatory

\begin{tabular}{|c|c|c|c|c|c|c|c|c|}
\hline Parameters & $C(n=8)$ & $O(n=7)$ & $H(n=8)$ & $O+H(n=8)$ & $C+\operatorname{SIF}(n=8)$ & $O+\operatorname{SIF}(n=8)$ & $H+\operatorname{SIF}(n=8)$ & $O+H+\operatorname{SIF}(n=8)$ \\
\hline \multicolumn{9}{|l|}{ Adipose Tissue } \\
\hline MDA ( $\mu \mathrm{Mol} / \mathrm{L})$ & $15.36 \pm 2.42$ & $30.54 \pm 8.61^{*}$ & $33.26 \pm 8.71^{*}$ & $45.38 \pm 7.26^{*}:, \neq$ & $13.71 \pm 4.43$ & $18.34 \pm 2.16^{*}$ & $17.09 \pm 5.11^{\phi}$ & $28.69 \pm 9.81^{\$}$ \\
\hline TAS $(\mu \mathrm{Mol} / \mathrm{L})$ & $1238.31 \pm 17.2$ & $706.88 \pm 64.63^{\star}$ & $639.65 \pm 51.11^{\star}$ & $513.43 \pm 55.32^{*}, \neq, \phi$ & $1250.4 \pm 448.1$ & $1186.36 \pm 161.03^{*}$ & $707.58 \pm 124.56$ & $892.09 \pm 306.42^{\$}$ \\
\hline MDA / TAS ratio & $0.012 \pm 0.003$ & $0.043 \pm 0.010^{*}$ & $0.052 \pm 0.014^{*}$ & $0.089 \pm 0.018^{*}, \neq, \phi$ & $0.012 \pm 0.005$ & $0.015 \pm 0.003^{*}$ & $0.024 \pm 0.008^{\phi}$ & $0.036 \pm 0.016^{\$}$ \\
\hline $\begin{array}{l}\text { MDA ( } \mu \mathrm{Mol} / \mathrm{mg} \\
\text { protein) }\end{array}$ & $0.62 \pm 0.09$ & $1.29 \pm 0.32^{*}$ & $1.35 \pm 0.35^{\star}$ & $1.79 \pm 0.28^{*},, \phi$ & $0.56 \pm 0.17$ & $0.67 \pm 0.12^{*}$ & $0.74 \pm 0.25^{\phi}$ & $1.07 \pm 0.36^{\$}$ \\
\hline $\begin{array}{l}\text { TAS }(\mu \mathrm{Mol} / \mathrm{mg} \\
\text { protein) }\end{array}$ & $50.11 \pm 7.32$ & $30.19 \pm 2.1^{\star}$ & $26.09 \pm 2.92^{*}$ & $20.3 \pm 2.35^{*, *, \phi}$ & $51.61 \pm 17.67$ & $43.39 \pm 7.74^{¥}$ & $30.68 \pm 5.85$ & $33.38 \pm 11.12$ \\
\hline MDA / TAS ratio & $0.012 \pm 0.003$ & $0.043 \pm 0.012^{*}$ & $0.052 \pm 0.014^{*}$ & $0.089 \pm 0.016^{* \neq, * \phi}$ & $0.012 \pm 0.001$ & $0.015 \pm 0.003^{*}$ & $0.024 \pm 0.008^{\phi}$ & $0.036 \pm 0.016^{\$}$ \\
\hline
\end{tabular}

All the values are expressed as mean $\pm S D$ ( $n=8$ per group). ${ }^{*} ¥, \phi P<0.05$ considered as statistically significant. ${ }^{*}-$ in comparison with $C$, $¥-$ in comparison with $O, \phi-$ in comparison with $\mathrm{H}, \$$ - in comparison with O + H, (one way ANOVA followed by Tukey post hoc test, SPSS version 19.0). C - Control, O - Ovariectomy, H - High Fat Diet, SIF - Soy Isoflavones, MDA -Malondialdehyde, TAS - Total Antioxidant Status.

Table 2: Effect of soy isoflavones extract on adipose tissue oxidative stress in an experimental model of post-menopausal obesity 
Citation: Panneerselvam S, Packirisamy RM, Bobby Z, Sridhar MG (2016) Protective Effect of Soy Isoflavones (from Glycine max) on Adipose Tissue Oxidative Stress and Inflammatory Response in an Experimental Model of Post-menopausal Obesity: The Molecular Mechanisms. Biochem Anal Biochem 5: 266. doi:10.4172/2161-1009.1000266

Page 5 of 7

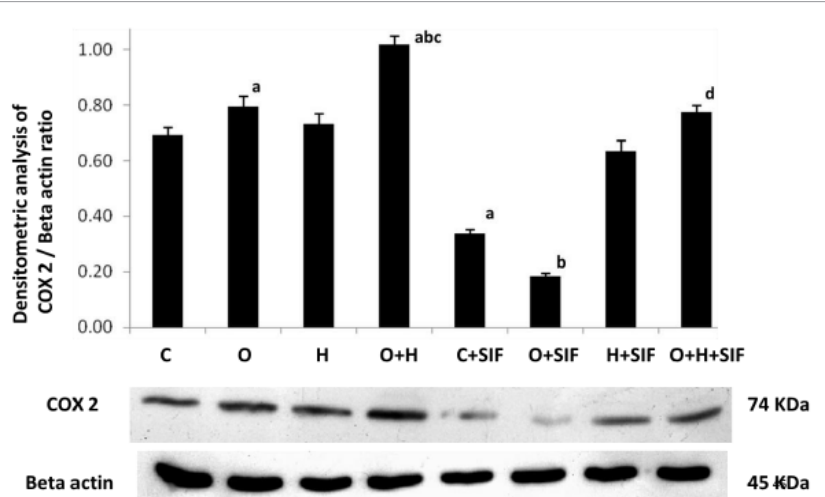

Figure 4 : Immunoblot and densitometric analysis of effect of soy isoflavones on cyclo- oxygenase 2 (COX2) protein expressions in adipose tissue of high fat fed ovariectomised female Wistar rats. Results expressed as mean \pm S.D. $\left(\mathrm{n}=3, \mathrm{P}<0.05\right.$ significant, ${ }^{a}$ in comparison with $\mathrm{C}$, in comparison with $\mathrm{O},{ }^{2}$ in comparison with $\mathrm{H}$, in comparison with $\mathrm{O}+\mathrm{H})$. C - Control, O - Ovariectomy, $\mathrm{H}$ - High Fat Diet, SIF - Soy Isoflavones. (One way analysis of variance with Tukey post hoc test, SPSS $\vee$ 16.0).

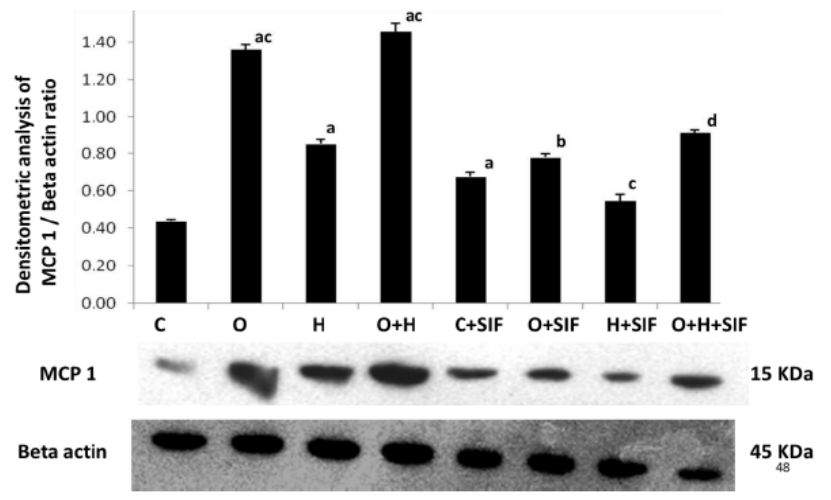

Figure 5: Immunoblot and Densitometric analysis of the effect of soy isoflavones on monocyte chemoattractant protein 1 (MCP 1) protein expression in adipose tissue of high fat fed ovariectomised female Wistar rats. Results expressed as mean \pm S.D. $\left(n=3, P<0.05\right.$ significant, ${ }^{a}$ in comparison with $C,{ }^{b}$ in comparison with $\mathrm{O},{ }^{C}$ in comparison with $\mathrm{H},{ }^{d}$ in comparison with $\left.\mathrm{O}+\mathrm{H}\right) . \mathrm{C}-$ Control, $\mathrm{O}-$ Ovariectomy, H - High Fat Diet, SIF - Soy Isoflavones. (One way analysis of variance with Tukey post hoc test, SPSS $\vee$ 16.0).

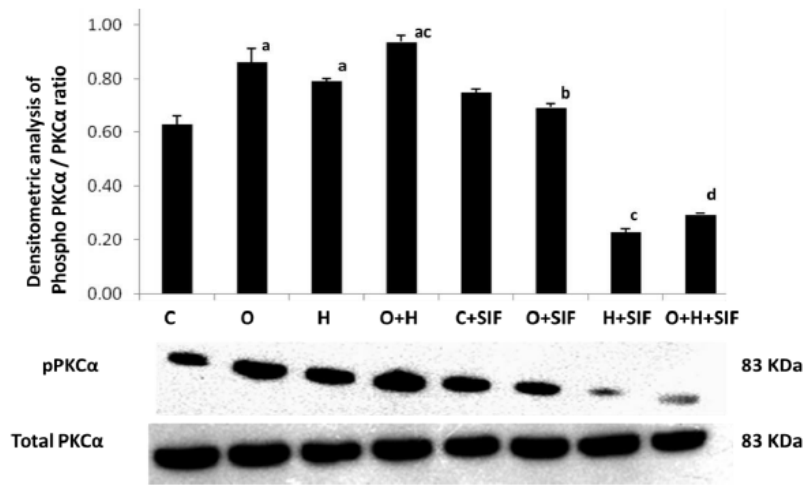

Figure 6: Immunoblot and Densitometric analysis of effect of soy isoflavones on activation of protein kinase $C$ alpha (PKC alpha) in adipose tissue of high fat fed ovariectomised female Wistar rats. Results expressed as mean \pm S.D.

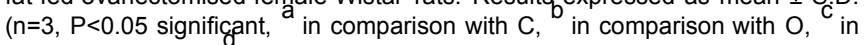
comparison with $\mathrm{H}$, in comparison with $\mathrm{O}+\mathrm{H}$ ). $\mathrm{C}$ - Control, $\mathrm{O}$ - Ovariectomy, $\mathrm{H}$ - High Fat Diet, SIF - Soy Isoflavones. (One Way Analysis Of Variance with Tukey Post Hoc Test, SPSS V 16.0) cytokine might have recruits the mono cytestothesite of inflammation and increased the secretion of inflammatory cytokines, with the resultant inflammatory response. Since adipose tissues as a major source of inflammatory cytokines, the increase in the adipose tissue mass observed in these rats might have enhanced the expression of these pro-inflammatory cytokines, with the resultant adipose tissue (AT) inflammation. This must have led to the increased levels of plasma inflammatory markers; TNFa, and CRP observed in these rats. It has been reported that in adiposity/obesity there is a remarkable shift in the pool of tissue macrophages from the alternatively-activated M2 type to the classically-activated M1 type, changing the secretion of cytokines from predominantly anti-inflammatory (M2) to proinflammatory (M1).

In the present study, both ovariectomy as well as high fat feeding in rats might have caused the shifting to M1 from M2 leading to increased production of pro-inflammatory cytokines and ultimately inflammatory response. The adipose tissue mass, plasma inflammatory markers and expression of these inflammatory proteins were further augmented when ovariectomy was followed by high fat diet, suggesting a synergistic role of postmenopausal state and intake of high fat diet in the development of AT inflammation. Treatment with soy isoflavones mitigates the expression of these inflammatory proteins and might have suppressed AT inflammation, emphasizing the anti-inflammatory property of soy isoflavones. The reduction in the mass of adipose tissue by soy isoflavones might have added to its anti-inflammatory activity.

Oxidative stress (OS), a pathological state of imbalance in the free radical defense system plays a vital role in the development of inflammation associated metabolic consequences; atherosclerosis and obesity. There are several mechanisms by which adiposity/obesity produces OS. It has been reported that, in obesity, the increased adipose mass produces adipokinecalled angiotensin II and Protein Kinase $\mathrm{C}$ which in turns witch on the transcriptional programs involved in the expression ofpro- oxidative enzyme NADPH oxidase leading to the enhanced production of ROS with the resultant oxidative stress [44,45].

In the present study, the expression of adipose tissue PKCa was upregulated in response to both ovariectomy and high fat diet. The upregulation of this protein might have induced NADPH oxidase, with the resultant increased ROS and ultimately oxidative stress. Previously we have reported the induction of NADPH oxidase (NOX4) in association with reduced expression of anti-oxidant proteins; SOD1 and GPx1 in ovariectomised rats as well as high fat fed rats [46]. These results suggest that the ovary ectomyas well as high fat diet induced oxidative stress through activation of PKCa. This is mediated by enhanced expression of NADPH oxidase in association with suppressed expression of anti-oxidant enzymes; SOD1 and GPx1. These results explain at least in part that the increased levels of adipose tissue lipid peroxidation (MDA) and reduced total anti-oxidant observed in the adipose tissue of the ovariectomised as well as high fat fed rats. Treatment with soy isoflavones significantly inhibited the PKCa activation and oxidative stress markers in the adipose tissue of these rats, emphasising its anti-oxidant property in improving the postmenopausal redox imbalance.

Previously studies have reported that the increased production of free radicals induced the inflammatory response by activation the classical signaling proteins such as COX2 and PKCa. This in turn further activates the free radicals generation through activation of NADPH oxidase [44]. Taken together, these observations suggest the concept that oxidative stress and inflammation participate in a vicious cycle, by which each of the two factors can recruit and amplify each other. This cycle plays a central role in the development of other metabolic complications associated with the 
Citation: Panneerselvam S, Packirisamy RM, Bobby Z, Sridhar MG (2016) Protective Effect of Soy Isoflavones (from Glycine max) on Adipose Tissue Oxidative Stress and Inflammatory Response in an Experimental Model of Post-menopausal Obesity: The Molecular Mechanisms. Biochem Anal Biochem 5: 266. doi:10.4172/2161-1009.1000266

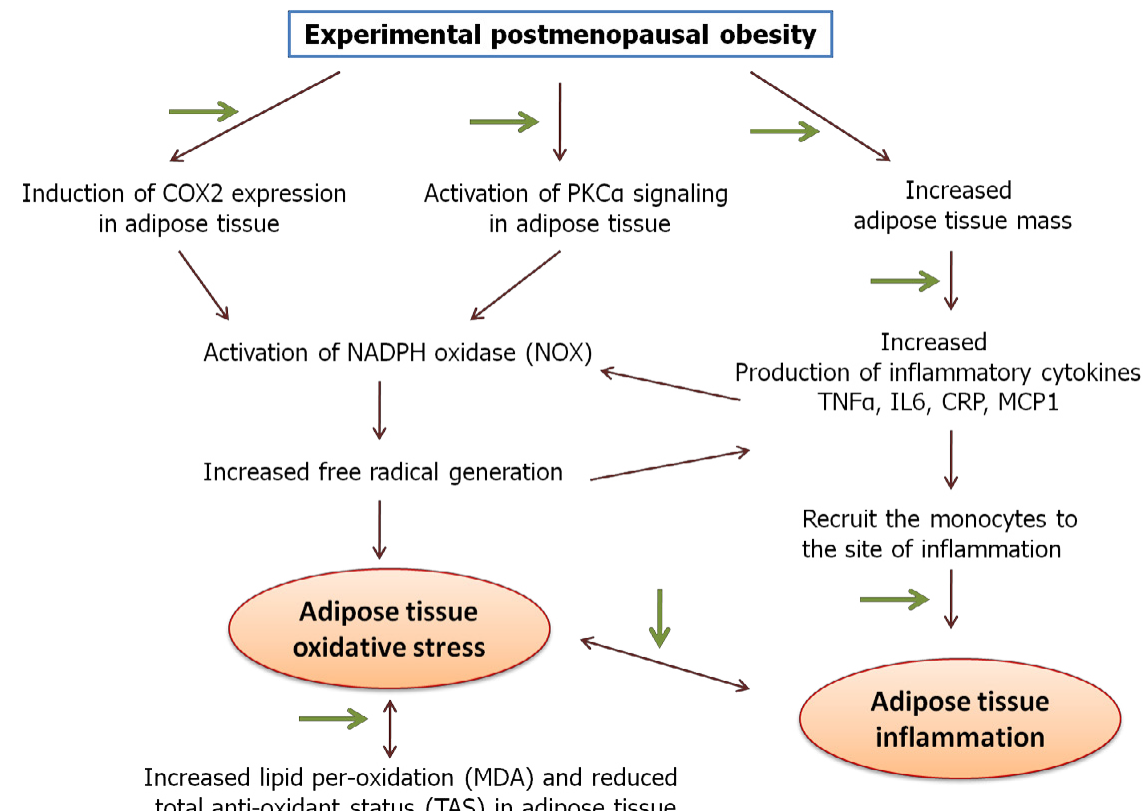

Figure 7: Schematic representation of possible mechanisms involved in the pathogenesis of oxidative stress and inflammatory response in postmenopausal obesity and protective effects of soy isoflavones. Red colour indicated the inhibitor effects of soy isoflavones. COX - Cyclo-Oxygenase, Pkca - Protein Kinase C Alpha, NADPH - Nicotinamide Adenine Dinucleotide Phosphate, NOX - NADPH Oxidase, TNF - Tumor Necrosis Factor, IL - Interleukin, CRP - C Reactive Protein, MCP - Monocyte Chemoattractant Protein, MDA - Malondialdehyde, TAS - Total Antioxidant Status.

postmenopausal population. Though, several molecular mechanisms amenable for the development of postmenopausal complications has been established, the etiological origin and management of metabolic complications concomitant with these complications remainunclear and the problem needs to be explored. This present study provides the evidence that both ovariectomy and high fat diet caused oxidative stress and inflammatory response, with a more augmented effects when both were associated. This suggests that there was a synergism between the postmenopausal state and intake of fat rich diet in the development of oxidative stress and inflammation. Treatment with soy isoflavones significantly restored the oxidative and inflammatory impairment and improved oxidative stress and inflammatory response, emphasising its anti-oxidant and anti-inflammatory properties in term of relieving the postmenopausal metabolic complications.

\section{Conclusion}

Both obesity and postmenopausal state per se developed adipose tissue oxidative stress and inflammatory response. The severities of these metabolic derangements were more pronounced when postmenopausal state co-existed with obesity. This suggests that women after menopause may restrict intake of fat rich diet particularly those are genetically predisposed with obesity. Treatment with soy isoflavones improves these metabolic complications, suggesting the use of this natural phytoestrogen as a strategy for relieving the metabolic consequences associated with postmenopausal obese populace. The schematic representation of the possible mechanisms involved in the pathogenesis of oxidative stress and inflammatory response in postmenopausal obesity and protective effects of soy isoflavones was illustrated in Figure 7.

\section{Acknowledgement}

The study was supported by intramural research funds sanctioned from host institute to the corresponding author and DST INSPIRE fellowship to the firs author. There was no commercial entity involved. The funding source had no role in study design, data analysis and interpretation. The corresponding author had ful access to all the data in the study and had final responsibility for the decision to submit for publication.

\section{Conflict of Interest}

We declare that we have no conflicts of interest.

\section{References}

1. Bal A, Unlu E, Bahar G, Aydog E, Eksioglu E, et al. (2007) Comparison of serum IL-1 beta, sIL-2R, IL-6, and TNF-alpha levels with disease activity parameters in ankylosing spondylitis. Clin Rheumatol 26: 211-215.

2. Franceschi C, Capri M, Monti D, Giunta S, Olivieri F, et al. (2007) Inflammaging and anti-inflammaging: a systemic perspective on aging and longevity emerged from studies in humans. Mech Ageing Dev 128: 92-105.

3. Toth MJ, Ades PA, Tischler MD, Tracy RP, LeWinter MM (2006) Immune activation is associated with reduced skeletal muscle mass and physical function in chronic heart failure. Int J Cardiol 109: 179-187.

4. Wellons M, Ouyang P, Schreiner PJ, Herrington DM, Vaidya D (2012) Early menopause predicts future coronary heart disease and stroke: the Multi-Ethnic Study of Atherosclerosis. Menopause 19: 1081-1087.

5. Davis SR, Castelo-Branco C, Chedraui P, Lumsden MA, Nappi RE, et al. (2012) Understanding weight gain at menopause. Climacteric 15: 419-429.

6. Teede HJ, Lombard C, Deeks AA (2010) Obesity, metabolic complications and the menopause: an opportunity for prevention. Climacteric 13: 203-209.

7. Loos BG (2005) Systemic markers of inflammation in periodontitis. J Periodontol 76: 2106-2115.

8. McFarlane SI, Muniyappa R, Shin JJ, Bahtiyar G, Sowers JR (2004) Osteoporosis and cardiovascular disease: brittle bones and boned arteries, is there a link? Endocrine 23: 1-10.

9. Ross R (1999) Atherosclerosis - an inflammatory disease. N Engl J Med 340: $115-126$

10. Willerson JT, Ridker PM (2004) Inflammation as a cardiovascular risk factor Circulation 109: II2-II10.

11. Baldini V, Mastropasqua M, Francucci CM, D'Erasmo E (2005) Cardiovascular disease and osteoporosis. J Endocrinol Invest 28: 69-72.

12. Elenkov IJ, lezzoni DG, DalyA, Harris AG, Chrousos GP (2005) Cytokine dysregulation, inflammation and well-being. Neuroimmunomodulation 12: 255-269. 
Citation: Panneerselvam S, Packirisamy RM, Bobby Z, Sridhar MG (2016) Protective Effect of Soy Isoflavones (from Glycine max) on Adipose Tissue Oxidative Stress and Inflammatory Response in an Experimental Model of Post-menopausal Obesity: The Molecular Mechanisms. Biochem Anal Biochem 5: 266. doi:10.4172/2161-1009.1000266

13. Weitzmann MN, Pacifici R (2006) Estrogen deficiency and bone loss: an inflammatory tale. J Clin Invest 116: 1186-1194.

14. Yasui T, Maegawa M, Tomita J, Miyatani Y, Yamada M, et al. (2007) Changes in serum cytokine concentrations during the menopausal transition. Maturitas 56: $396-403$

15. Suzuki A, Abdelmalek MF (2009) Nonalcoholic fatty liver disease in women. Womens Health (Lond Engl) 5: 191-203

16. McKenzie J, Fisher BM, Jaap AJ, Stanley A, Paterson K, et al. (2006) Effects of HRT on liver enzyme levels in women with type 2 diabetes: a randomized placebo-controlled trial. Clin Endocrinol (Oxf) 65: 40-44.

17. Rossouw JE, Anderson GL, Prentice RL, LaCroix AZ, Kooperberg C, et al (2002) Risks and benefits of estrogen plus progestin in healthy postmenopausal women: principal results From the Women's Health Initiative randomized controlled trial. JAMA J Am Med Assoc 288: 321-333.

18. Frith J, Newton JL (2010) Liver disease in older women. Maturitas 65: 210-214.

19. Lethaby A, Marjoribanks J, Kronenberg F, Roberts H, Eden J, et al. (2013) Phytoestrogens for menopausal vasomotor symptoms. Cochrane Database Syst Rev 12: CD001395.

20. Kagan A, Harris BR, Winkelstein W Jr, Johnson KG, Kato H, et al. (1974) Epidemiologic studies of coronary heart disease and stroke in Japanese men living in Japan, Hawaii and California: demo- graphic, physical, dietary and biochemical characteristics. J Chronic Dis 27: 345-364.

21. Cassidy A, Hooper L (2006) Phytoestrogens and cardiovascular disease. $J$ Brithish Menopause Soc 12: 49-56.

22. Hall WL, Vafeiadou K, Hallund J, Bugel S, Koebnick C, et al. (2005) Soyisoflavone-enriched foods and inflammatory biomarkers of cardiovascular disease risk in postmenopausal women: interactions with genotype and equol production. Am J Clin Nutr 82: 1260-1268.

23. Curran EM, Judy BM, Newton LG, Lubahn DB, Rottinghaus GE, et al. (2004) Dietary soy phytoestrogens and ERalpha signalling modulate interferon gamma production in response to bacterial infection. Clin Exp Immunol 135: 219-225.

24. Verdrengh M, Jonsson IM, Holmdahl R, Tarkowski A (2003) Genistein as an anti-inflammatory agent. Inflamm Res 52: 341-346.

25. Li FN, Li LL, Yang HS, Yuan XX, Zhang B, et al. (2011) Regulation of soy isoflavones on weight gain and fat percentage: evaluation in a Chinese Guangx minipig model. Animal 5: 1903-1908.

26. Jiang G , Lili L, Juexin F , Bin Z, Oso AO, et al. (2015) Dietary soy isoflavones differentially regulate expression of the lipidmetabolic genes in different white adipose tissues of the female Bama minipigs. Biochemical and Biophysical Research Communications. 461: 159-164.

27. Blum A, Lang N, Peleg A, Vigder F, Israeli P, et al. (2003) Effects of oral soy protein on markers of inflammation in postmenopausal women with mild hypercholesterolemia. Am Heart J 145: e7.

28. Hilpert KF, Kris-Etherton PM, West SG (2005) Lipid response to a low-fat diet with or without soy is modified by $\mathrm{C}$-reactive protein status in moderately hypercholesterolemic adults. J Nutr 135: 1075-1079.

29. Nasca MM, Zhou JR, Welty FK (2008) Effect of soy nuts on adhesion molecules and markers of inflammation in hypertensive and normotensive postmenopausal women. Am J Cardiol 102: 84-86.

30. Beavers KM, Serra MC, Beavers DP, Cooke MB, Willoughby DS (2009) Soymilk supplementation does not alter plasma markers of inflammation and oxidative stress in postmenopausal women. Nutr Res 29: 616-622.

31. Storlien LH, James DE, Burleigh KM, Chisholm DJ, Kraegen EW (1986) Fa feeding causes widespread in vivo insulin resistance, decreased energy expenditure, and obesity in rats. Am J Physiol 251: E576-E583.

32. Lee YB, Lee HJ, Kim KS, Lee JY, Nam SY, et al. (2004) Evaluation of the preventive effect of isoflavone extract on bone loss in ovariectomized rats. Biosci Biotechnol Biochem 68: 1040-1045.

33. Liu Z, Zhang X, Li L, Zhang W, Cui W, et al. (2008) Effects of lactational exposure to soy isoflavones on reproductive system in neonatal female rats. Basic Clin Pharmacol Toxicol 102: 317-324.

34. Yagi K (1976) A simple fluorometric assay for lipoperoxide in blood plasma. Biochem Med 15: 212-216.

35. Benzie IF, Strain JJ (1996) The ferric reducing ability of plasma (FRAP) as measure of "antioxidant power": the FRAP assay. Anal Biochem 239: 70-76.

36. Kurlak LO, Green A, Loughna P, Broughton Pipkin F (2014) Oxidative stress markers in hypertensive states of pregnancy: preterm and term disease. Fron Physiol 5: 310.

37. Chung CP, Schmidt D, Stein CM, Morrow JD, Salomon RM (2013) Increased oxidative stress in patients with depression and its relationship to treatment Psychiatry Res 206: 213-216.

38. Hotamisligil GS (2006) Inflammation and metabolic disorders. Nature 444: 860 867.

39. Greenberg AS, Obin MS (2006) Obesity and the role of adipose tissue in inflammation and metabolism. Am J Clin Nutr 83: 461S-465S.

40. Fang J, Yang L, Zhang R, Zhu X, Wang P (2015) Are there differences between Sprague-Dawley and Wistar rats in long-term effects of ovariectomy as a model for postmenopausal osteoporosis? Int J Clin Exp Pathol 8: 1491-1502.

41. Rogers NH, Perfield JW 2nd, Strissel KJ, Obin MS, Greenberg AS (2009) Reduced energy expenditure and increased inflammation are early events in the development of ovariectomy-induced obesity. Endocrinology 150: 21612168 .

42. Kim WK, Choi EK, Sul OJ, Park YK, Kim ES, et al. (2013) Monocyte chemoattractant protein-1 deficiency attenuates oxidative stress and protects against ovariectomy-induced chronic inflammation in mice. PLoS One 8 e72108.

43. Ding F, Yao J, Zhao L, Mao Z, Chen S, et al. (2013) Ovariectomy induces a shift in fuel availability and metabolism in the hippocampus of the female transgenic model of familial Alzheimer's. PLoS One 8: e59825.

44. Sharma K (2014) Obesity, oxidative stress, and fibrosis in chronic kidney disease. Kidney Int Suppl (2011) 4: 113-117

45. Touati S, Montezano ACl, Meziri F, Riva C, Touyz RM, et al. (2015) Exercise training protects against atherosclerotic risk factors through vascular NADPH oxidase, extracellular signal- regulated kinase $1 / 2$ and stress-activated protein kinase/c-Jun N-terminal kinase downregulation in obese rats. Clin Exp Pharmacol Physiol 42:179-185.

46. Sankar P, Zachariah B, Vickneshwaran V, Jacob SE, Sridhar MG (2015) Amelioration of oxidative stress and insulin resistance by soy isoflavones (from Glycine max) in ovariectomized Wistar rats fed with high fat diet: the molecular mechanisms. Exp Gerontol 63: 67-75. 